\title{
Positioning JIBS as an interdisciplinary journal
}

John Cantwell

\author{
Editor-in-Chief
}

and

Mary Yoko Brannen

Deputy Editor

Journal of International Business Studies (2011) 42, I-9. doi: I 0. I057/jibs.2010.50
It is with great honor and pleasure, as well as in keen anticipation of what we are confident can be achieved by the journal, that we begin this three-year term as the new editors of the Journal of International Business Studies. We are both long-term members of the Academy of International Business (AIB), and readers of JIBS for almost as long as we can remember. Over the years, we have watched the ever more promising development of JIBS, of which we now enjoy more issues per year, and in which the gradual progression in the depth and breadth of its content has laid the foundations for what we hope and believe will be a new phase in the flourishing of the journal in the period that now lies ahead. In this respect, we must begin by paying tribute to all the Editorsin-Chief of the journal that have preceded us, whose conscientious efforts have not gone unrewarded.

Naturally enough, we owe a debt of gratitude especially to our two most recent predecessors, Arie Lewin and Lorraine Eden. Before Arie, JIBS was the long-established leading specialist journal within the field of international business (IB) studies, a partially hidden gem for those of us in the know. After Arie, it was recognized much more widely as a top ("A") journal among scholars of business and management even outside the IB field. Arie raised the stature of JIBS in business schools as a whole, an achievement that was crucial not just for the journal, but for the continued vitality of our field. Before Lorraine, if we are brutally honest, JIBS had remained a rather shambolic affair in terms of its administrative structure and procedures. In fact, it is a credit to the earlier editors that they managed to achieve so much with such limited resources and systems of support, most of which were concentrated in a single office that used to hold responsibility for everything! After Lorraine, JIBS has become an exemplar of efficient organizational systems, and well-managed and clearly understood procedures for conduct, including a pioneering Code of Ethics. We should also acknowledge here with warm appreciation the critical contributions that have been made by the AIB Executive Secretariat and especially by Managing Editor Anne Hoekman, as well as by David Bull and his wonderful staff at Palgrave, whose degree of commitment to the journal and support for it has been second to none. When we look at how radically JIBS has been transformed under Arie's and Lorraine's leadership, suffice to say that but for the sea changes which they have brought about, we would have had to think very hard before offering our services as editors. But with the firm foundation that they have given us, and with the resulting opportunities that the journal now has in front of it, stepping forward as editors is a decision we have made with ease as well as pride. 
As is doubtless by now well known within our IB community, John Cantwell (of Rutgers Business School, Newark and New Brunswick) has become the Editor-in-Chief (EIC) of JIBS for 2011-2013. When he was first asked to consider applying to become the next JIBS editor, one of the first things he did was to approach Mary Yoko Brannen (of INSEAD) to ask for her support. While his background lay in the Reading School, grounded in the economic analysis of IB, hers can be found in the cross-cultural studies perspective on IB - two of the most important strands of thinking on IB. In the terminology of the management discipline, one of these strands of scholarship pertains to the macro elements of $\mathrm{IB}$, while the other relates to the micro aspects of IB. Although the advantages of interaction between selected elements of these two different forms of analysis have only recently been emerging in IB scholarship, as cross-over scholars providing bridges for our home disciplines to strategic issues concerning the multinational enterprise (MNE), we see these two sides of the IB subject area as complementary, and in need of being fully explored.

From the time of our initial discussion of the JIBS Editorship onwards, this became a collaborative partnership between us, and we have adapted the previously established editorial structure for JIBS to reflect this cooperation. Thus, John Cantwell as EIC of JIBS will be supported by Mary Yoko Brannen as Deputy Editor. As we will explain in what follows, the rationale behind this new editorial team structure is consistent with our vision of reinforcing and extending the positioning of JIBS as multidisciplinary in scope, as well as interdisciplinary in content and methodology. In our judgment, the IB field has already broadened in the scope of research interests that it encompasses to the extent that this objective has become more difficult to achieve successfully through the central oversight of a single editor. But perhaps more importantly, to achieve our goal it is critical that we put out the right "signals" to the professional communities that make up our field or could participate in it. We wish to more effectively reach out to those with IB interests who have thus far published only (or mainly) within the main publication outlets of their own discipline rather than in JIBS, to demonstrate that JIBS is open to highquality IB scholarship from across a wide range of disciplinary origins and to novel kinds of IB research that synthesize insights derived from different theoretical traditions. We both feel that we must build upon the established base of IB theory and findings (standing upon the shoulders of giants, as the saying goes), and at the same time we are open to new approaches and methods in seeking to do so, as well as of course to the extension and further refinement of those approaches that are already more familiar to the JIBS readership.

\section{STRATEGIC OBJECTIVES FOR IBBS}

Our basic objective is to extend and to deepen the philosophy for JIBS, and the strategy for the positioning of the journal, which has been worked out during her term by the outgoing EIC, Lorraine Eden. Given a matrix comprised of disciplines arranged by column and subject areas arranged by row, in our view Lorraine quite rightly reached the conclusion that JIBS needs to be positioned as a "row" journal. That is, JIBS covers the entire row or spectrum of IB studies across the full range of disciplines (columns) that have some bearing on the IB field. However, as pointed out in the further exposition of this view by a sub-group of the previous editorial team (Cheng, Henisz, Roth, \& Swaminathan, 2009), there is a critical distinction that needs to be made between interdisciplinary research, which mixes ideas drawn from different disciplines, and multidisciplinary approaches, in which a series of separate contributions from different disciplines occur independently or sequentially.

Since most of the submissions currently received by JIBS, and most of the articles actually published, are written from the perspective of a specific discipline, the existing editorial approach tends to be multidisciplinary in character. That is, when working in some unidisciplinary perspective, authors of JIBS articles are expected to explain why what they have done should be of interest to IB-oriented scholars from other disciplinary backgrounds. In this context the focus has been on widening the multidisciplinary span of JIBS to broaden the range of disciplines represented by the readership and the contributors to the journal. Thus, the Statement of Editorial Policy was amended by the previous editors to include a new sentence to say that: "JIBS is an interdisciplinary journal that welcomes submissions from scholars in business disciplines (e.g., accounting, finance, management, marketing) and from other disciplines (e.g., economics, political science) if the manuscripts fall within the JIBS domain statement." 
We wish to extend the "row journal" philosophy in two significant ways: First, to increase the range and variety of disciplines represented in JIBS, to encourage a greater appreciation for their methodological diversity, and a greater sophistication in utilizing such diverse approaches as and where applicable. Second, to more actively encourage and attract papers that are written from the outset in an interdisciplinary mold. We wish to flag up that we are keen to receive papers which combine and integrate theories and concepts that are taken from or can be traced to origins in different disciplines. By facilitating the development of interdisciplinary concepts, theories and ideas that synthesize and interrelate arguments taken from different disciplinary perspectives, we aim to bring into our fold new interests in IB and new recruits from the disciplines by offering them intellectually novel and more integrative approaches. A more fully interdisciplinary journal will offer a distinctive venue for those who at present work largely or entirely within the confines of a specific discipline. It will enable them to think more deeply about the content and subject matter of IB by combining ideas that are already familiar to them with other complementary themes from hitherto unexplored related approaches.

However, lest we be misunderstood, we wish to stress that we believe the greatest potential for developing new interdisciplinary research directions in IB will tend to come less often from current outsiders being drawn into IB work and in so doing widening in their interests beyond those in their own discipline. Instead, it is likely to come more often from those of us already active in IB research becoming ambitious to address more complex questions than those which are typically formulated when relying on the standard assumptions and the narrowing of focus usually found within disciplines. In addressing issues that relate to a wider range of interactions, IB scholars will be able to leverage our deep contextual knowledge - one of our strongest assets - while combining this with ideas picked up from outside our mother discipline. Yet we do feel strongly that if we in the IB research community ourselves develop more in this direction, the potential appeal of our work to others that for now are active only within their own discipline will be increased, by providing an intellectual bridge for them to reach outwards as well as inward. It would also ensure that JIBS will develop a unique character among the top business journals, enabling it to gain greater recognition from researchers in each of the disciplines whose ideas contribute to the intellectual mix provided by IB studies.

Our core editorial group provides a partnership of research active scholars who reflect the interdisciplinary perspective for JIBS in our own work; and represent different parts of the spectrum of the various disciplines, subject areas, geographical areas, methodologies and approaches which characterize IB studies. In terms of a disciplinegrounded division of labor between our central editorial team, John Cantwell as EIC covers in his span of research expertise economics, history, geography, philosophy and policy, and Mary Yoko Brannen as Deputy Editor represents the range of anthropology, sociology, psychology, linguistics and policy. In addition, we complement and reinforce one another in terms of our methodological training, John being primarily trained in economics with a strong quantitative orientation as well as having a solid training in qualitative methods, and Mary Yoko being trained as an ethnographer as well as having a solid training in multi-methods and quantitative theoretical triangulation. Each of our Area Editors is deeply grounded and respected in his or her own primary discipline(s) but at the same time is dedicated to the notion of combining ideas taken from that discipline with other complementary perspectives on similar issues in the IB field. Of note, in order to better balance the macro/micro breadth of the editorial team, and in order to better connect with scholarship in two sub-fields which have until now been somewhat disconnected from other IB studies, we have created area editor positions in international human resource management and cross-cultural management. These areas were previously handled by a single editor. This will enable us to give better care to manuscripts that focus on both the domains of cross-cultural management and international human resources. We have also taken care to ensure that our editorial team spans scholars in schools in Asia and Europe as well as North America.

\section{AN ELABORATION ON THE RATIONALE FOR POSITIONING JIBS AS AN INTERDISCIPLINARY JOURNAL}

We base our thinking here on Dunning (1989), who argued that changes in real-world IB practice were requiring greater cross-functional integration, and this in turn called for interdisciplinary studies. A greater cross-functional integration in IB operations 
implies an increase in transaction costs as a share of the total costs of conducting business activity. This in turn calls for a more holistic form of analysis that directly addresses issues of the common governance of business structures, which individual disciplines with their own more narrowly formulated questions are not well designed to achieve. Hence, Dunning (1989) argued that interdisciplinary studies, when properly organized, lower the transaction costs of IB study itself, by more effectively bringing together and integrating potentially connectable ideas.

Of course, the trend toward greater crossfunctional integration is not the only relevant real-world trend, and there are some other counteracting influences, which we need to take into account. In fact, there has been a continuing tension between two conflicting real-world trends that goes back arguably to the first industrial revolution, but which has been considerably accentuated since 1945, and has become especially evident in recent times. These are the trends toward (1) a steadily increased intensity of knowledge development and usage, which has given rise to pressures for more focused specialization, and hence a separation of disciplines and even of sub-disciplines; and (2) a need for new combinations of knowledge across fields, which creates pressures towards less specialization, and which has led to the formation of some "bridge" disciplines like engineering or management which connect some more traditional natural science or social science disciplines with real-world practice.

This tension is reflected in the discussion of Cheng et al. (2009), who tended to emphasize that within academia the first of these trends has been strongly reinforced by the administrative structures of universities and most professional associations or communities, which are typically organized by discipline. However, it is our contention that the current tide is gradually shifting the balance from the first of these trends toward the second, and that this creates a huge potential opportunity for IB studies, if our subject area is identified as interdisciplinary and relatively open to innovative new approaches.

In support of our explicitly positioning JIBS as an interdisciplinary journal, we offer seven arguments, of which the first six are adapted from Dunning (1989).

(1) With globalization, research of a unidisciplinary kind in the IB subject area is and will continue to be increasingly published in the relevant disciplinary ("column") journals, as well as in specialist IB ("cell") journals. We add merely that we are aware that we will still continue to receive many essentially unidisciplinary submissions for JIBS, and we will continue to welcome them, so we intend JIBS to simply expand the boundaries of inclusiveness, rather than to set up some new criteria for exclusion (other than those already well articulated in the Editorial Policy statement of the domain of IB research, and in the continuing editorial request to explain why a paper should be of interest to JIBS readers in other disciplines).

(2) Yet because the practice of IB is instead ever more integrative in character, it increasingly requires interdisciplinary analysis. Many of the more important and interesting issues arise at the intersections between disciplines. There are also an increasing number of global contagion effects whose impact runs across functions and fields of study as well as across countries or space, as well illustrated in the recent financial crisis and business recession.

(3) However, the AIB (JIBS) has not yet made a sufficient transition from multidisciplinary to interdisciplinary research, partly because of the artificial barriers created by differences in methods across disciplines. As methodological variety becomes more accepted, and as the guidelines for rigorous research in different areas of IB studies become better established and more widely understood, the potential for new kinds of cross-fertilization of ideas should become greater.

(4) Interdisciplinary research needs to be driven primarily by issues, broadly defined paradigms or phenomena of interest to most IB scholars, rather than by functional approaches. The more complex are the issues or phenomena to be addressed, the more likely it is that the need for relevant interdisciplinary approaches will become apparent to the more critically minded scholars in each discipline.

(5) Our efforts to encourage this kind of interdisciplinary work should aim to bring into our fold new interests in IB and new recruits from the disciplines, by offering them interdisciplinary perspectives that are relevant to the questions they are already working with, but which cannot be found within the confines of their own mother discipline.

(6) Unless IB provides these kinds of distinctive integrated intellectual frameworks there may be 
a danger in the future of our subject area being hollowed out to the various disciplines, as stressed by Cheng et al. (2009). However, on a more positive note, if $J I B S$ succeeds as a more interdisciplinary journal, then through an increase in cross-citation with the various disciplines we are more likely to mutually enhance our respective standings. This calls for JIBS to become recognized within each discipline as contributing a distinctive deeply contextual and interdisciplinary perspective on IB that would allow for a wider range of relevance and applications for hitherto more narrowly defined unidisciplinary questions.

We note that this prospect for a multidisciplinary application of ideas and cross-citation of publications is not without precedent - for example, the interdisciplinary ideas of Nelson and Winter in the subject area ("row") of innovation studies have come to be widely cited across disciplines such as business history, geography or regional science, organizational sociology, management, and policy (indeed perhaps more so than in their own mother discipline of economics!).

As an aside on this issue, and as a consequence of the increasing prospects for interdisciplinary synergy in place of multidisciplinary substitution effects, we take a largely relaxed and indeed even confident view of the impact on JIBS of the launch of new IB journals, and the reinvigoration of others under new editorship. This is in part because we hold a more optimistic view of IB research than Cheng et al. (2009), who posited that it may be in a state of decline in terms of its impact, insight and status. We believe on the contrary that our field is growing and steadily becoming more widely recognized - as witnessed by a growth in AIB membership, the trend increase in AIB conference attendance, and the widening acceptance of JIBS as an "A" journal supported by the journal's now impressive citation impact factor ranking. Therefore, we believe that the pool of IB articles available to JIBS and other journals that publish IB research is rising, and that the increasing interest in IB within some sub-disciplines such as strategy is to our mutual benefit.

Of course, to ensure that JIBS continues to receive a healthy share of papers related to global strategy requires that JIBS occupy a distinctive position relative to "cell" journals in the domain of international management or strategy. We are of the view that creating this kind of complementarity between IB-related journals is simply an important special case of the need for JIBS to become more clearly identified as an interdisciplinary "row" journal. Indeed, the need to foster a synergy between IB journals associated respectively with the row, the column and the cell becomes ever more important with the way in which journal rankings are now being formulated. By building up a nexus of relevant cross referencing of IB work that appears in different journals a rising tide will likely lift all boats further.

(7) We can add that in the 20 years since Dunning (1989) wrote his article, we have seen a marked acceleration in the trend towards fragmentation within disciplines into sub-fields, and hence the proliferation of "sub-column" and "cell" journals. We expect this trend to continue, partly because it has now become exceedingly difficult for any new generalist disciplinary journals to establish themselves against the top ranking journals of a discipline that are of long standing. However, the recent trend towards well regarded sub-discipline journals, and still more cell journals, facilitates the scope for a connective row journal, which in our judgment may well represent the way of the future.

No doubt most IB authors will continue to begin to formulate a focused research question on any topic from within the perspective that is associated with the cell that represents their primary discipline. However, this should usually lead them to other more complex questions that can be satisfactorily addressed only by drawing on materials and methods developed outside their own immediate discipline. While there may certainly continue to be pressures from within disciplines to by-pass or ignore such more fundamental and challenging questions, most of the best scholars are generally aware too of the limitations of restricting oneself to what can be achieved from within a disciplinary silo in isolation. So this is also in part a chicken and an egg problem, that if there are no good and established interdisciplinary journals in a subject area, then it becomes difficult to get published research that ventures outside the customary norms of a discipline. If this is true, then creating such an outlet should call forth exciting new lines of research that the most able and promising scholars may previously have been reluctant to undertake. 
THE ADVANTAGES OF THE STEADY BROADENING OF IB RESEARCH PERSPECTIVES At one time, around the middle or late 1970s, it might be argued that IB research had a unifying paradigm, built around answering a "big question". The big question was "why does the multinational enterprise (MNE) exist?", and the internalization paradigm enabled us to address that question, with (for a time) an ever-increasing degree of sophistication. A range of allied questions was raised at various degrees of distance from the central theme, such as what are the implications for the impact of MNEs on home and host countries, or for the relationships between MNEs and governments, or for the development of MNE strategies which balanced the economic (internalization) advantages of global integration against the requirements for national responsiveness. However, the big question was one that turned out to be characteristic of the context of that era of the 1970s, of the early state of the development of the IB field at that time, and of the training in economics of many of the leading scholars in the field. Both the question itself, and the framework within which it was successfully answered, came to seem increasingly limiting as the range of research interests in the IB field has expanded, and the range of disciplines that are represented in IB scholarship has become broader.

We believe that a big question and a single unifying paradigm are features of a program of research conducted within a discipline, or in which one discipline is dominant relative to others. This is what enables scholarship in an area to be narrowed and consolidated around some focal theme or issue, and which provides the basis for a common analytical expression of the nature of what is at stake among researchers. Without a shared set of restrictive underlying theoretical assumptions, and a shared interpretive framework, intellectual efforts proceed instead along a variety of perspectives that may lead work in different directions. In this respect, recognizing that the IB field is now at a point where it is receptive to the development of interdisciplinary frameworks is an acknowledgment of a trend in research in our area that has been slowly progressing over a 30-year period. In IB we can no longer rely upon or follow the strictures of a specific discipline. The days of a single "big question" or a unifying paradigm are long gone, and unlikely to return. We need to recognize that groupings from each of our primary disciplines will continue to have their own agenda
- a kind of dual commitment, to IB and to their discipline - but when we come together as an IB community we can appreciate the value of the complementary contributions of other relevant approaches, or the need for the background knowledge and settings that they provide us with.

Of course, our lack of sharpness of analytical focus relative to the disciplines may sometimes be a weakness, but the greater complexity and practical relevance of the questions we can address and our capabilities as natural bridges of deep contextual knowledge of business in the world at large to our disciplinary homes is an advantage of our field. When research programs are working well, these two kinds of research contribution will tend to run in harmony with one another, and to complement each other - one specialized in focus and depth, and the other treating connections and complexity in a broader system of relationships or combination of levels of analysis. In other words, to advance knowledge in a balanced and meaningful way, the disciplines need us as much as we need them. What an interdisciplinary field such as IB offers is an analytical interaction between a wider diversity of views. With the benefit of hindsight, the achievements of our field to date that have multiple research applications, such as the development of the OLI paradigm or the deeper understanding of the role of contextualization in international knowledge transfer, have been a step along the way. They have laid a common foundation for a progressive conversation between different perspectives that enables an increasing interchange to be conducted across various streams of research that might otherwise have found it difficult to relate to one another.

\section{ADMINISTRATIVE ARRANGEMENTS FOR THE JOURNAL, AND THE WAY FORWARD}

With only some minor modifications, we will adhere to all the operational practices that have been so well developed by the previous editorial team. We will continue with the existing system of recommended deadlines for editors and authors, the rationale for desk rejects, the framework for accepting or rejecting papers, and for communicating decisions to authors, and so on. We have largely retained the previous JIBS Statement of Editorial Policy, but we have adapted and extended it to add clarity for authors, and the new version of the Statement is at the front of this issue and for convenience we have also reproduced it below in 
an Appendix to this article (it has already appeared for some time on the JIBS website, which most authors refer to when submitting their work). We have also further regularized the policy for special issues of the journal by considering special issue proposals collectively once a year, to ensure that the selection process is more competitive and open and the best ideas come forward.

We have reinstated the role of an initial Reviewing Editor (RE), which job has been filled by Alvaro Cuervo-Cazurra (of the University of South Carolina). Alvaro is now conducting a first-stage screening of all papers submitted to JIBS. He writes a brief review of each paper for the attention of either the EIC or Deputy Editor, depending upon the disciplinary area and topic of the paper. Once a paper reaches us, generally not long after it has been submitted, we decide whether to desk reject it, or to allocate it to one of our Area Editors for further review. We may address the desk reject process in a future editorial, but the primary reason why papers are centrally desk rejected is a lack of fit with the journal. Despite the clarity of our Statement of Editorial Policy in this respect, we still receive many papers whose subject lies outside the IB domain, and perhaps this is inevitable, especially given our desire to attract new strands of research and new scholars to our field. All we would add for now is that JIBS policy is usually to allow papers that have been desk rejected to be resubmitted to JIBS, so long as the authors take to heart the issues that we raise as reasons for desk rejection, and carefully revisit and amend their paper accordingly. Of course, this will often imply that the conceptualization and the framing of a paper has to be thoroughly reworked in order to rectify a lack of fit with the purposes of the journal. It is only when papers have been sent out for review and then rejected that as a general rule we do not allow them to be resubmitted. So in this respect, and because the decision comes much quicker, desk rejection can sometimes be better and more helpful for authors than rejection following review.

Papers that are not centrally desk rejected are forwarded to one of our Area Editors, with our own accompanying comments as well as the initial report of the RE. The Area Editors read the papers and make their own assessment, in addition to the comments and suggestions on a paper they may have received from us. They then decide whether to send a paper out for review (if they do not desk reject it, which in their case would be usually on the grounds of an inadequacy of contribution to the relevant stream of literature), and if indeed they do send it out, they invite suitable reviewers. In other words, papers that are dispatched for review have already been seen and commented upon by three of the editorial team early in the process, and we believe that this should help us in the balanced evaluation of each paper and the quality of editorial guidance of the subsequent review process. As we now say in the Statement of Editorial Policy, the goal of JIBS is to publish insightful, innovative and impactful research on IB. So, as Editors, we are especially keen to try and identify between us, and with the help of our reviewers, what is or might be (and for that matter, what is not!) the most "insightful, innovative and impactful" aspects of each paper we receive.

In the light of our earlier remarks, we are keen to receive submissions of the very best IB papers of scholars in areas of research in which in the past JIBS may not always have been thought of as the first choice outlet. We have already mentioned that international human resource management and cross-cultural management are two such areas. Others include international finance, international innovation studies, and international economic geography. In each of these areas there is a literature by specialists that has been developed largely at a distance from the IB scholarly community, and which has appeared mainly in discipline or subject-specific journals. There is everything to be gained for both sides from a greater degree of interaction between research in the IB field and these subject specialists who work on the international aspects of their areas. In our view, highquality papers that speak both to scholars in the IB field and to the relevant area specialists or disciplines are more likely to also become highly impactful papers. Where such conversations are successfully developed, then JIBS will naturally be positioned as the premiere journal for that interchange. It will also be recognized as an " $\mathrm{A}$ " journal for the best international articles of authors in each of the relevant disciplines or areas.

In concluding, we would like to return to one of our central themes, in order to reiterate our belief in the strong prospects that we have already from within the existing readership of JIBS to broaden our frameworks of analysis even without attracting any new scholars to our field, and without initiating any complicated and cumbersome new joint projects between teams of scholars from different disciplines. In our view of our community, we 
believe that IB scholars benefit oftentimes from extensive life experience of multiple cultures. Perhaps this is what has drawn us to IB research in the first place, at least in part. Therefore, as individuals, we have the potential to bring to our research unique contextual insights, cross-contextual perceptual acuity, and flexibility and openness to multiple systems of sense making or to different ways of thinking about the world and analyzing it. Although individual disciplinary interests may

\section{REFERENCES}

Bello, D., Leung, K., Radebaugh, L., Tung, R.L., \& van Witteloostuiin, A. 2009. From the editors: Student samples in international business research. Journal of International Business Studies, 40(3): 361-364.

Cheng, J. L. C., Henisz, W. J., Roth, K., \& Swaminathan, A. 2009. From the editors: Advancing interdisciplinary research in the field of international business: Prospects, issues and challenges. Journal of International Business Studies, 40(7): 1070-1074.

Dunning, J. H. 1989. The study of international business: A plea for a more interdisciplinary approach. Journal of International Business Studies, 20(3): 411-436.

\section{APPENDIX}

\section{JIBS Statement of Editorial Policy}

The Journal of International Business Studies (JIBS) is the top-ranked journal in the field of international business. The goal of JIBS is to publish insightful, innovative and impactful research on international business. JIBS is multidisciplinary in scope, and interdisciplinary in content and methodology.

JIBS seeks to publish manuscripts with cuttingedge research that breaks new ground, rather than merely making an incremental contribution to international business studies. Manuscripts should address real-world phenomena, problems or puzzles; recognize that their contributions stand on the shoulders of prior researchers to highlight what is interesting and different; and include a clear statement of what it is they contribute to international business research. JIBS is particularly interested in publishing innovative papers that start up or redirect a line of inquiry, integrate across disciplines rather than being single disciplinary, and are multi-level (micro, meso and/or macro) rather than single-level studies. Theories whose central propositions are distinctively international are encouraged, as are theories where both dependent and independent variables are international. range from economics, finance, strategy, to organization theory or human resource management and so on, as IB scholars we bring to the field our own unique identities that are often decidedly intercontextual. As such, we would encourage our contributors to express their interdisciplinary nature to a greater extent than is commonplace currently, by writing and submitting articles that showcase as opposed to suppress this core and competitive attribute.

Manuscripts that provide different perspectives, often deliberately controversial or challenging to mainstream views, are welcome if they advance international business theory.

JIBS does not publish manuscripts that merely criticize previous work without providing new insights into how the limitations of previous work can be resolved. JIBS is interested in papers that are constructive in nature, and so which suggest how our established theories or received understandings of issues in international business can be positively adapted or revised, or extended to offer new perspectives and insights on newly emerging international phenomena.

JIBS welcomes submissions in any of the six sub-domains of international business studies: (1) the activities, strategies, structures and decision-making processes of MNEs; (2) interactions between MNEs and other actors, organizations, institutions, and markets; (3) the cross-border activities of firms (e.g., intrafirm trade, finance, investment, technology transfers, offshore services); (4) how the international environment (e.g., cultural, economic, legal, political) affects the activities, strategies, structures and decision-making processes of firms; (5) the international dimensions of organizational forms (e.g., strategic alliances, mergers and acquisitions) and activities (e.g., entrepreneurship, knowledgebased competition, corporate governance); and (6) cross-country comparative studies of businesses, business processes and organizational behavior in different countries and environments.

Submissions qualify as having substantial international business content, and therefore potentially suitable for JIBS, where at least one of the six sub-domains listed above is a primary focus of attention within the main line of argument being developed in the paper. The major theme of a JIBS 
paper should highlight the insights that can be derived for the international aspects of business activity as such. Papers in which international business is in the background, or in which international business issues are secondary or peripheral to the main argument being developed, are not suitable for JIBS.

$J I B S$ is an interdisciplinary journal that welcomes submissions from scholars in business disciplines (e.g., accounting, finance, management, marketing) and from other disciplines (e.g., economics, political science) if the manuscripts fall within the JIBS domain statement. Papers are especially welcome which combine and integrate theories and concepts that are taken from or that can be traced to origins in different disciplines. JIBS is a methodologically pluralistic journal. Single-country studies are welcome as long as international business or one of its six sub-domains is the central focus of, and not peripheral to, the study. Quantitative and qualitative research methodologies are both encouraged, as long as the studies are methodologically rigorous. Conceptual and theory- development papers, empirical hypothesis-testing papers, and case-based studies are all welcome. Mathematical modeling papers are welcome if the modeling is appropriate and the intuition explained carefully.

JIBS does not publish manuscripts about teaching materials/methods, literature reviews or manuscripts aimed solely at a practitioner audience. Manuscripts that make no theoretical contribution to international business studies (e.g., replication studies) or that have no specific relevance to the domain of international business studies should not be sent to JIBS. Empirical submissions utilizing student samples are usually discouraged, except where a strong, explicit justification for their legitimacy is provided (see Bello et al., JIBS, 2009, $40,3,361-364)$. Papers that classify or rank journals or scholars along various dimensions are generally discouraged.

Submissions to JIBS must follow the journal's Style Guide, including formatting, length and references. Poorly written or structured papers will be promptly returned to the authors. 